\title{
“Semi-hétero nem é gente": uma análise da bifobia em espaços de cibersociabilidade homossexual
}

\author{
("Half-straights aren't even people": \\ an analysis of biphobia in homosexual cibersociability spaces)
}

("Semi hetero ni siquiera es gente": un análisis de bifobia em espacios de cibersociabilidad homosexual)

\section{Inácio dos Santos Saldanha ${ }^{1}$}

RESUMO: Este artigo tem como objetivo analisar, com inspiração na etnografia virtual, declarações 'bifóbicas', isto é, negativas à bissexualidade e a indivíduos bissexuais, em dois espaços de cibersociabilidade homossexual: o fórum Pan, e uma publicação da página Resistência Gay, no Facebook, ambos acessados majoritariamente por homens gays cisgênero. As discussões entre os jovens homossexuais destacam a negação da existência da bissexualidade, a associação dos bissexuais com a contaminação do HIV, com um conjunto de comportamentos imorais e com uma tendência aos privilégios heterossexuais. Os resultados aproximam-se da enumeração de “estratégias do apagamento bissexual”, proposta por Kenji Yoshino (2000).

PALAVRAS-CHAVE: Bissexualidade. Bifobia. Internet. Etnografia virtual.

\begin{abstract}
This article aims at analyzing, inspired by the Virtual Ethnography 'biphobic' declarations, that is, the negative ones to bisexuality and bisexual individuals, in two cibersocial spaces: Forum Pan and a publication of the Facebook page Resistência Gay, both mostly accessed by cisgender gay men. The homosexual men's discussions show the denial of the existence of bisexuality, the linking of bisexuals to HIV contamination, a roll of immoral behaviors and a tendency to heterosexual privileges. The results are near to the listing of "strategies of bisexual erasure" proposed by Kenji Yoshino (2000).

Keywords: Bisexuality. Biphobia. Internet. Virtual ethnography.
\end{abstract}

Resumen: Este artículo tiene como objetivo analizar, con inspiración en la etnografía virtual, declaraciones 'bifóbicas', es decir, negativas para la bisexualidad y las personas bisexuales, en dos espacios de cibersociabilidad homosexual: el foro Pan y una publicación de la página Resistência Gay en Facebook, a los que acceden principalmente hombres homosexuales cisgénero. Las discusiones entre los jóvenes homosexuales destacan la negación de la existencia de la bisexualidad, la asociación de los bisexuales con la contaminación del VIH, con un conjunto de comportamientos inmorales y con una tendencia hacia los privilegios heterosexuales. Los resultados se acercan a la enumeración de 'estrategias de encubrimiento bisexual' propuesta por Kenji Yoshino (2000).

Palabras clave: Bisexualidad. Bifobia. Internet. Etnografía virtual.

1 Licenciado em História pela Universidade do Estado do Pará. E-mail: inaciosants@gmail.com. 


\section{Introdução}

'Bifobia'. O termo polêmico que vem ganhando alguma repercussão em espaços virtuais ainda é pouco discutido e estudado por pesquisadores no Brasil. A composição da palavra remete à homofobia - a hostilidade contra pessoas homossexuais (BORRILLO, 2010) -, mas sugere uma discriminação direcionada a pessoas bissexuais e que funciona de uma forma distinta da homofobia. De acordo com Mulick e Wright Jr. (2002, p. 47), o termo foi empregado pela primeira vez em um estudo por Kathleen Bennett, em 1992, muito embora haja registros fotográficos de cartazes com a palavra bi-phobia em passeatas nos Estados Unidos desde a década de 1980. De lá para cá, a palavra vem sendo empregada por militantes e estudiosos para explorar diversas facetas de uma discriminação que seria advinda de heterossexuais $e$ de homossexuais.

Alguns autores brasileiros têm apresentado trabalhos sobre a bifobia no país, principalmente no campo do movimento LGBT $^{2}$ (CAVALCANTI, 2007; JAEGER, 2018; LEÃO, 2018; LEWIS, 2012). A primeira etnografia a se debruçar sobre o tema da bissexualidade na internet no Brasil foi a tese de doutoramento de Ismar Inácio dos Santos Filho (2012), que observou a identidade bissexual em salas de bate-papo virtual frequentadas por homens brasileiros e ouviu de seus entrevistados que a bissexualidade costuma ser associada à 'safadeza'. Ádria Souza Ramos de Azevedo (2016), por sua vez, analisou as abordagens da bissexualidade ao longo de dez anos de atividade do portal eletrônico de notícias G1, constatando “apagamento ou deslegitimação” dessa orientação sexual enquanto identidade.

O objetivo deste artigo não é analisar a formação da bissexualidade enquanto identidade na internet, ou o silêncio e a desconsideração pelo tema na mídia eletrônica, mas sim focar em discursos bifóbicos enunciados em dois endereços eletrônicos frequentados por homens homossexuais. Os endereços foram o fórum virtual de entretenimento Pan e um publicação da página Resistência Gay, no Facebook, na qual a bissexualidade foi debatida.

Considerando a rede mundial de computadores um espaço de intensa produção cultural, meio de articulação de comunidades e ampliação de redes sociais, ainda que sem seguir "os mesmos modelos de comunicação e interação das comunidades físicas” (CASTELLS, 2002, p. 445), esta observação foi realizada com inspiração nas discussões metodológicas da etnografia virtual. Definida por Christine Hine como "uma metodologia de investigação sobre a internet

2 Lésbicas, gays, pessoas bissexuais e de identidades aproximadas, pessoas do espectro trans, pessoas intersexo, pessoas do espectro assexual e outras identidades mais fragmentadas ou fluidas; uma vez que existe uma larga discussão sobre a amplitude da sigla, ela é empregada aqui em sua forma simplificada, em decorrência de seu uso mais corrente nos espaços dessa pesquisa, a não ser quando a fonte usa outra variação. 
para o estudo empírico sobre seus usos atuais” (HINE, 2000, p. 10, tradução minha), a etnografia virtual ou netnografia tem sido explorada e mesmo problematizada por diversos estudiosos desde a virada do século XX para o XXI. Hine, ao defender a adoção deste método, chama a atenção para os cuidados que o pesquisador deve ter em suas observações: entre outras, observar até que ponto a internet afeta as relações sociais em relação ao tema estudado, e quais as diferenças entre os processos no meio on-line e no off-line, uma vez que os dois correspondem entre si de maneiras complexas.

\section{Conceitos e bases de análise}

A experiência de pessoas bissexuais não é um tema muito explorado nos estudos de gênero e sexualidade em geral, mesmo na literatura questionadora da teoria queer (ANGELIDES, 2006). Atualmente, porém, existem algumas proposições esquemáticas de como a bifobia é promovida e percebida na sociedade, geralmente alinhadas com narrativas militantes de onde essa noção se originou, e nem mesmo o seu nome é um consenso. Alguns autores em língua inglesa preferem o termo binegativity (DYAR; FEINSTEIN, 2018), algo como "binegatividade”, em português. O sociólogo Miguel Obradors-Campos (2011) dividiu suas manifestações em oito tipos: ‘exploração’, ‘imperialismo cultural', ‘desempoderamento', ‘marginalização’, 'heteronomia’, ‘violência’, 'alienação’ e ‘estigmatização’. Sua divisão é um esforço declarado de alinhar a bifobia às formas de "opressão estrutural”, como o racismo, o sexismo e a homofobia. Outro conceito utilizado largamente para pensar uma discriminação da bissexualidade é o apagamento bissexual, às vezes associado ou não ao conceito de bifobia. Um dos seus principais desenvolvedores, o jurista Kenji Yoshino, defendeu que o apagamento é produzido por um “contrato epistêmico” de motivações políticas, no qual heterossexuais e homossexuais vêm investindo historicamente:

A existência de um contrato bilateral de apagamento bissexual é amparada pelo fato de que ambos heterossexuais e homossexuais usam as mesmas estratégias de apagamento da bissexualidade. Há três estratégias: (1) apagamento da classe, (2) apagamento do indivíduo e (3) deslegitimação. Essas estratégias implicam a aceitação de afirmações fortemente bem-sucedidas sobre a existência bissexual - a primeira estratégia não reconhece a categoria 'bissexualidade'; a segunda a reconhece, mas exclui um indivíduo dela; e a terceira aceita a bissexualidade individual como uma identidade estável, mas a estigmatiza. (YOSHINO, 2000, p. 400, tradução minha)

Sem jamais igualar as posições de poder (ou os benefícios políticos adquiridos a partir desse 'contrato') de homossexuais e heterossexuais, Yoshino defendeu que os dois grupos têm um interesse comum em manter dicotomizadas as práticas e delimitadas as identidades nas quais baseiam suas políticas e padrões culturais. Uma das várias polêmicas em sua teoria é a inclusão 
de ofensas, estigmas e demais atitudes violentas como manifestações de um 'apagamento', uma vez que elas colocam a bissexualidade em evidência, mesmo que atribuindo-lhe sentidos negativos. Para ele, a deslegitimação seria uma forma de apagamento porque reduz a orientação bissexual a meros comportamentos ou desvios, negando sua existência enquanto orientação sexual. A ativista israelense Shiri Eisner (2013) foi responsável por aproximar os conceitos de Obradors-Campos e de Yoshino, situando a bifobia nas atitudes que manifestam as estratégias de apagamento da bissexualidade, obedecendo a enumeração de Obradors-Campos.

Já no Brasil, Camila Dias Cavalcanti (2007) apresentou uma lista publicada em 2006 pelo boletim do Núcleo Bis, um dos primeiros grupos de bissexuais do país, de dez 'mitos' cultivados sobre as pessoas bissexuais, dos quais listo alguns: "Bissexualidade não existe”; "Bissexuais são emocionalmente imaturos e não sabem o que querem”; “Bissexuais são promíscuos, eles/elas querem sexo e não compromisso"; "Bissexuais sofrem menos preconceito”; "Um homem bissexual vai deixá-lo por uma mulher e vice-versa. Não se pode confiar neles/as”; “Bissexuais espalham HIV/Aids”; “São todos/as casados/as, enrustidos/as ou fazem swing”. Trabalhando cada um de forma interdiscursiva, Cavalcanti usou as respostas no próprio boletim e as falas de membros do Núcleo Bis para afirmar a falsidade de todos eles. Os autores têm defendido, de uma maneira geral, que a formação histórica de uma oposição binária rígida na sexualidade (homo vs. hétero), renegou a bissexualidade a um lugar ambíguo e marginal, ou melhor, a um não-lugar.

Pelo que foi observado, os dois espaços analisados neste estudo são frequentados majoritariamente por homens cisgênero homossexuais (o que já era notório pela grande fama do primeiro e pela proposta do segundo), e seguem padrões de comunicação e convivência específicos do meio virtual - sem cair na pressa de considerar o virtual como um mero oposto do real (CASTELLS, 2002). Uma observação geral das páginas deixou claro logo de cara que a bissexualidade não é um tema recorrentemente abordado em nenhum dos dois, mesmo quando se trata de discussões centradas em políticas ou subculturas LGBT. O site Pandlr, às vezes referido como a Pandlr, abriga o fórum virtual conhecido como Pan (além de dois outros fóruns alternativos), com conversas descontraídas sobre entretenimento e, ocasionalmente, sexualidade. Ele originou-se de uma comunidade para o público da Rádio Jovem Pan na extinta rede social Orkut. O fórum é dividido em tópicos criados pelos usuários, nos quais discutem alguma variedade de temas, quase sempre relacionados à música pop norte americana. Embora existam regras e moderadores, os internautas expressam-se quase livremente, muitas vezes provocando as ameaças de banimento. Nos comentários destacados a seguir, chamam a atenção as imagens de mulheres fora de seus contextos originais: são GIFs animados, largamente utilizados na internet 
junto às mensagens como complemento da comunicação. O GIF (sigla para Graphic Interchange Format, ou Formato de Intercâmbio Gráfico, em português) é um formato digital de imagem que possibilita a impressão de movimento, como em um vídeo, mas em arquivos de tamanho menor, o que facilita o envio e a reprodução.

Atualmente eles são muito associados à repetição inerente ao que convencionou-se chamar 'meme’: conteúdos (imagens, frases, vídeos) cuja reprodução tem um efeito cômico. Por isso, os GIFs serão considerados como parte das falas analisadas. Muitos memes usados por jovens LGBT no Brasil são criados e popularizados a partir da Pandlr, o que evidencia a relativa relevância deste endereço na cibercultura LGBT do país. Nas discussões entre os usuários do fórum, ofensas e outras expressões agressivas contrastam com a comicidade dos GIFs enviados em anexo, gerando um sentido de deboche; dependendo da cena representada na imagem, eles também podem conferir dramaticidade ou reforçar a agressividade que o internauta deseja manifestar. Embora autores como Manuel Castells tenham percebido a desinibição, a sinceridade e a solidariedade proporcionadas pelas comunidades virtuais e pelas ferramentas de comunicação multimídia, uma importante ressalva dada por Christine Hine é a de que a interpretação de declarações expressas na internet é constituída de incertezas: estando protegidas em razões de distância e identificação, é comum que pessoas se expressem de maneira exagerada ou artificial, e, assim, os comentários não podem ser todos lidos de maneira literal.

Neste texto, indico o endereço das imagens usadas pelos internautas quando elas aparecem. Como existe o risco de serem perdidas caso os sites em que estão hospedadas deixem de existir, acrescento no corpo do texto uma captura de imagem de cada GIF animado, de forma a dar à inteligibilidade do artigo uma maior durabilidade, por precaução. Também mantive a ortografia e a pontuação dos internautas, uma vez que elas dão a fluidez e o caráter informal e específico das discussões online. As mensagens geralmente aparecem sem iniciais maiúsculas ou sem as vírgulas e o ponto final, ou ainda com diversas letras trocadas; por ser o site um espaço de livre expressão, também são comuns os palavrões nos comentários. Acrescento que a definição das imagens é baixa e sua definição geralmente é prejudicada, o que acelera o seu envio durante as discussões.

A Resistência Gay foi criada em 2015 para apresentar uma proposta de dissidência em relação ao 'movimento LGBT convencional', que seus administradores acusam de promover uma disputa pelo papel central que os homens gays têm tido historicamente em seus ambientes e discussões. A descrição apresentada pelos organizadores da página a define como "de conteúdo político e orientação essencialista”, isto é, indica que ela aborda a homossexualidade como um dado natural humano, o qual precisa ser socialmente respeitado, incluído e valorizado por isso. A 
publicação analisada a seguir consiste em uma lista de razões pelas quais as pessoas bissexuais não sofreriam bifobia e tampouco homofobia, e estando próximas da condição de privilégio das pessoas heterossexuais. Também são destacados alguns comentários de seguidores da página.

A observação do fórum Pan, que requereu a criação de uma conta para acessar o conteúdo, permitiu a compreensão das regras e dos usos da comunidade, mas sem interferências ou entrevistas. A bissexualidade tornou-se tema de discussão em três tópicos: um no qual a bissexualidade do cantor estadunidense Frank Ocean foi questionada, outro no qual a bissexualidade da também cantora estadunidense Lady Gaga foi questionada, e outro no qual a própria existência da bissexualidade foi colocada em questão. Esforcei-me para reproduzir os comentários de forma a dar uma visão ampla das discussões, mas, em geral, elas avançavam em nada e perdiam-se em bate-bocas e na repetição impositiva de opiniões; o artigo tem, ao todo, comentários de trinta pessoas diferentes. Quase todas as que discutiram na Pandlr estão representadas aqui (o que seria impossível de fazer caso a análise fosse de algum tópico específico sobre música, os quais são muito mais comentados), mas apenas cinco das dezenas de comentários da publicação da Resistência Gay serão apresentados, pois, neste caso, o centro da análise é o texto dos administradores da página, e os comentários apresentavam ideias muito semelhantes, com pouca ou quase nenhuma discordância. Veremos um por um.

\section{Acusados: Frank Ocean e Lady Gaga}

Um dos primeiros tópicos no fórum Pandlr a debater a bissexualidade foi criado na discussão de música e intitulado "FRANK OCEAN: Conheça o (falso Bi) PALMITEIRO!", abordando a vida sexual do cantor Frank Ocean, que assumiu publicamente sua atração por homens e mulheres (identificando-se como gay) e trouxe esse tema para suas músicas. (VÍRGULA, 2012) Os comentários no tópico questionavam a integridade da identidade e do discurso assumidos por Ocean ao envolver-se, segundo matérias utilizadas na discussão, apenas com homens, sendo estes todos brancos (quando ele também levanta questões raciais em sua obra enquanto artista negro). A raça e a orientação sexual do cantor bifurcam a discussão, uma vez que os usuários do fórum não as interligam de maneira efetiva em nenhum momento. Por isso, apresento apenas declarações que se referiram à bissexualidade. As primeiras:

Internauta 1: a bissexualidade precisa ser combatida e eu vou lutar contra isso Internauta 2: eu não apoio essa doença chamada bissexualismo de forma alguma Internauta 3: tive um namorado bi que me traiu com metade da facul. [Figura 1] 
Dois comentários agressivos se destacam: o internauta 1 afirma que a bissexualidade precisa ser combatida e que ele próprio lutará contra ela (o que é claramente uma brincadeira), embora não diga o que vê de errado na orientação bissexual. O segundo, em certa medida surpreendente, refere-se à bissexualidade como uma doença, usando o termo 'bissexualismo', semelhante ao 'homossexualismo' que atualmente é associado à histórica definição da homossexualidade como patologia na literatura médica (MACRAE, 2018, p. 35). Em minha observação do fórum, embora eu tenha percebido o uso corriqueiro da palavra 'doença' para depreciar os mais diversas gostos e comportamentos, é no mínimo curioso que um homossexual se refira a uma orientação sexual dessa forma, quando a própria homossexualidade foi patologizada por cerca de um século.

Figura 1 - Gretchen, em uma cena do reality show A Fazenda, exibido pela TV Record, do qual participou em 2012.

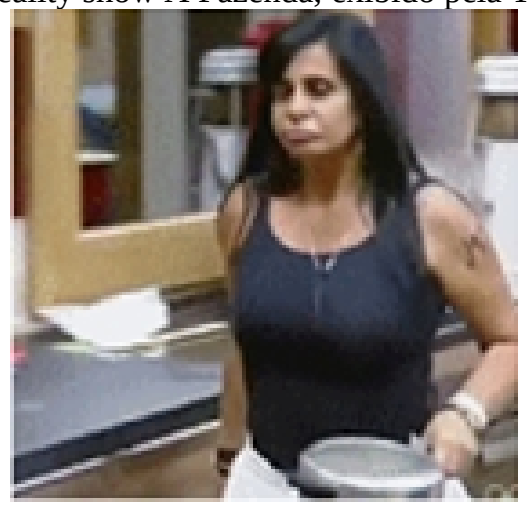

Fonte: https://bityli.com/B6TrA

Embora os primeiros comentários sejam pouco claros sobre o porquê de posições tão negativas à bissexualidade, a questão vai sendo aos poucos elucidada. O internauta 3 alude a um ex-namorado infiel, sem que ninguém tenha trazido o tema da infidelidade para a discussão; sua associação imediata entre a vida sexual de um homem bissexual e a sua experiência amorosa desastrosa com outro homem bissexual é automática. O jovem usa um GIF animado da cantora Gretchen (Figura 1). Na cena, a cantora discute com alguém em uma cozinha antes de pegar uma panela de pressão e se afastar irritada ou chateada, o que sinaliza o rancor do internauta. A crença de que pessoas bissexuais em geral são infiéis, mencionada mais acima (CAVALCANTI, 2007), começa a se manifestar.

\footnotetext{
Internauta 4: nada dói mais que um homem bi te trocar por mulher [Figura 2] Internauta 3: [respondendo ao internauta 4] HIV te assusta? [Figura 2] Internauta 3: Bissexual lê-se maior exportador de DSTs. [Figura 2] Internauta 5: [respondendo ao internauta 3] Falou merda Internauta 6: Bissexuais que espalharam a Aids Internauta 3: [com a intenção de corrigir o internauta 6] Ele é bicha
} 
A Figura 2 parece indicar tédio ou desaprovação por parte dos internautas 3 e 4. Quando o internauta 4 fala da infidelidade bissexual, o internauta 5 brinca: "HIV te assusta?”. A transmissão do vírus causador da Aids, a qual foi amplamente apresentada como uma doença de homossexuais e de outros grupos considerados promíscuos na década de 1980 (MACRAE, 2018, p. 78-87), é um estigma redirecionado sem pudor para outro grupo.

Figura 2 - Gretchen pisca enquanto encara algo ou alguém com os seus braços cruzados

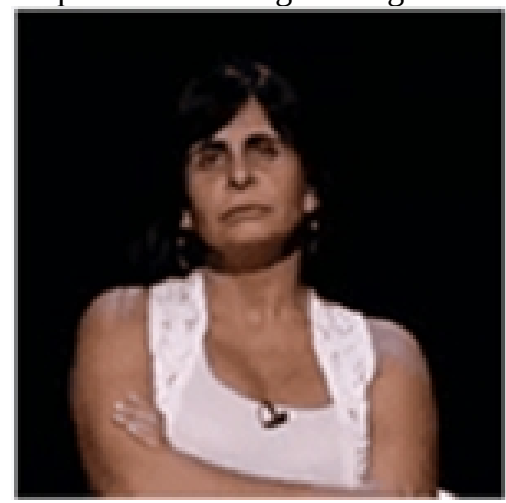

Fonte: https://bityli.com/SDvGj

O internauta 3 pareceu achar que esse tema não cabia ali, pois Ocean não seria bissexual. É interessante notar que, enquanto os homens bissexuais já eram acusados pela população heterossexual, e pelas instituições desta, de serem uma 'ponte' transmissora do HIV desde a mesma década de 1980 (FACCHINI, 2005, p. 171-172), aqui pessoas homossexuais que os acusam³ . Um novo comentário prossegue o raciocínio dizendo "Bissexual lê-se maior exportador de DSTs”, e provoca a revolta de outro usuário, embora não fique claro se este é homossexual ou bissexual. Em uma crescente repetição de GIFs da cantora Gretchen, a discussão começa a tomar novos rumos.

Internauta 7: Um artista bi tem mais mídia que um gay?

Internauta 3: [respondendo ao internauta 7] Tecnicamente sim, basta ver o histórico de artistas bissexuais que obtiveram sucesso midiático.

Billie Joe Armstrong, David Bowie ou até Mick Jagger.

Frank está aquém de todos os citados, porém a bissexualidade sempre foi um artifício pra chamar atenção.

Internauta 8: Mas ele era bi ou hetero no início de carreira mesmo, tem um monte de músicas dele que dão a entender que ele já dormiu com mulheres, porém, atualmente, acho que ele é somente gay, deve dizer que é bi só pra suavizar e harmonizar a fanbase. Agora ele só se relacionar com homem branco, creio que acaba sendo porque há poucos negros famosos e gay assumidos nos eua, e grande maioria lgbtq é pobre e com ideias muito incoerentes com a de um artista. [Figura 1]

Ao questionamento sobre se artistas bissexuais têm mais visibilidade na mídia, o internauta 3 responde que sim, ‘comprovando' com apenas três exemplos de artistas bissexuais

3 Fala-se em uma associação semelhante feita entre a relação com as mulheres bissexuais e o contágio de HIV em espaços lésbicos. (LEÃO, 2018, p. 35-37) 
de grande sucesso (Billie Joe Armstrong, David Bowie e Mick Jagger), e afirma que a bissexualidade é "um artifício para chamar atenção", o que sugere que os outros artistas se apresentaram como bissexuais para se promover. Em relação ao cantor Frank Ocean, o internauta 8 sugere que ele já foi heterossexual ou bissexual, mas tornou-se gay. Os comentários dão a entender que a bissexualidade chama atenção em um artista, sendo mais facilmente aceita que a homossexualidade. Sua suposição de que Ocean é ‘atualmente’ gay, parece partir do princípio de que a orientação sexual é concebida a partir dos relacionamentos do indivíduo, como um padrão comportamental, sem considerar a constituição de seu desejo ou sua própria subjetividade e intimidade. A bissexualidade torna-se uma fase ou um mero padrão comportamental.

Novamente na discussão de música, um tópico intitulado "LADY GAGA: a bissexual que só se relaciona com homens” ironiza a bissexualidade da cantora Lady Gaga, que se assumiu bissexual em 2009 na TV americana (HARRISON, 2017); o usuário que criou o tópico alegou que a artista só se relacionava com homens, e a maior parte dos comentários concordou com ele, aproveitando para se referir à artista com ofensas misóginas. De forma semelhante ao questionamento da sexualidade de Ocean, este tópico parte do princípio de que uma pessoa só é bissexual quando definitivamente se relaciona com homens e mulheres com a mesma frequência. Segundo reportagem da revista estadunidense Billboard, essas acusações não eram incomuns, e a própria cantora chegou a afirmar que "Não é mentira que eu sou bissexual e gosto de mulheres, e qualquer um que tente transformar isso em 'ela diz que é bissexual por marketing', isso é uma puta mentira. É assim que sou e é assim que sempre fui” (HARRISON, 2017, tradução minha). Os comentários seguintes:

Internauta 9: ela eh a prova que a bissexualidade não existe, cristal mesmo [Figura 3] Internauta 10: definiu 98\% dos bi [alguns outros usuários reagem com GIFs em que Gretchen ri, para concordar] Internauta 11: kkkkkkkkkkkkkkkkkkkkkkk ai amore eu te amo, mas agora que n precisa mais do mijo das gays, e já ta com 30 anos não fica bem pra imagem né?

Os internautas 9 e 10, um deles usando um GIF em que Gretchen aparece confusa, brincam ao dizer que Lady Gaga, ao ser uma falsa bissexual, comprovaria a falsidade da própria bissexualidade. 
Figura 3 - Em algum lugar fechado, o rosto de Gretchen discutindo com alguém

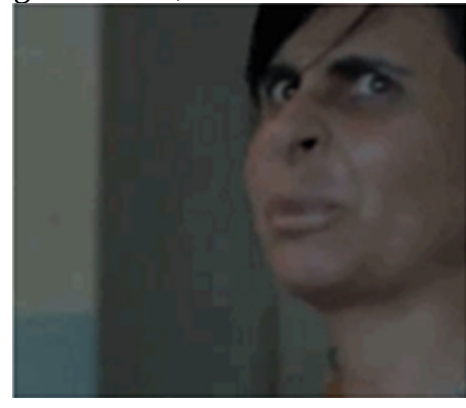

Fonte: https://bityli.com/F80CP

O internauta 11, por sua vez, ri ao dizer que a cantora não usa mais a identidade bissexual para se promover, provavelmente porque (mais ou menos na época em que a discussão na Pandlr ocorreu) Lady Gaga voltou atrás e se definiu como uma 'aliada' da comunidade LGBT, novamente na televisão (REYNOLDS, 2017). Dois anos depois, a artista desenvolveu melhor sua posição em um discurso em frente ao Stonewall Inn, na celebração dos cinquenta anos da revolta que levou o nome do lugar (TENBARGE 2019); afirmou que não deve ser considerada parte da comunidade 'apesar' de gostar de mulheres às vezes, e que não pretendia (ao se considerar igual ao seu público majoritariamente gay) enfraquecer a luta que eles tentavam fortalecer. Obradors-Campos chamaria de 'alienação' a essas contradições baseadas em uma hierarquia política de práticas. Mesmo sem considerar a identidade bissexual como uma condição inata que deve ser reivindicada ou "descoberta”, alguns autores têm sugerido que a marginalização da bissexualidade no campo político pode interferir no processo de identificação de pessoas que acabam se afastando dela (CALLIS, 2013). Ainda assim, é imprudente projetar interpretações gerais em casos muito pessoais, mesmo os mais publicizados, como fizeram os usuários do fórum ao negar a existência da bissexualidade através da artista.

\section{4. $O$ perigo bissexual: extremos opostos}

O terceiro tópico, e o mais comentado de todos, não foi inserido em nenhuma discussão específica, como os de música, sendo publicado como um 'tópico OFF'. O título "Bissexualidade não existe +17 " dá origem a um largo debate; o nome adverte que é uma discussão para usuários maiores de 17 anos, uma vez que aborda um tema sexual de forma explícita. A discussão inicia da seguinte maneira:

Internauta 12 [criador do tópico]: onde já se viu uma poc chupar e dar o rabo a um homem E depois ir comer a esposa?

Internauta 13: Claro q existe sua filha da puta desgracada

Internauta 14: Existir existe, infelizmente

Não podemos fazer nada, apenas tentar evitar contato 
O termo 'poc' é uma forma de indicar homens afeminados e não heterossexuais com diversas implicações que não cabem aqui. O criador do tópico refere-se como um absurdo à possibilidade de um mesmo homem assumir a posição sexual receptiva para outro homem e ainda assumir a posição sexual ativa com uma mulher. O usuário parte do princípio lógico de que, ou alguém gostaria de uma coisa, ou gostaria de outra. As preferências sexuais seriam limitadas. O internauta 14 afirma que a bissexualidade, na verdade, existe, mas que bissexuais devem ser evitados. Mas quem deve evitá-los? Os homens gays? Ou as demais pessoas? Os outros internautas apresentam suas considerações:

Internauta 15: Eu achei que já tinha passado essa modinha de dizer que Bissexuais não existem, como sempre Gays sendo nojentos, depois que apanharem na rua não venham criar tópico chorando na PAN [Figura 4]

Internauta 12: a verdade incomoda [Figura 5]

Internauta 16: Não existe relação bissexual

Bissexual namorando com alguém do gênero oposto e casal hétero são a mesma coisa e disfrutam dos mesmos privilégios pela sociedade do que um casal hétero

Internauta 17: [respondendo ao internauta 16] fatos.

até mesmo porque se a pessoa deseja outro homem, estando com uma mulher, é porque ele é um gay enrustido

O internauta 15 é o primeiro a criticar a postura dos outros, chamando os gays de nojentos; o tom extremamente agressivo de seu comentário é atenuado por um GIF de Lolly Vômito se divertindo em um campo com uma bola, o que acrescenta ao comentário um tom sarcástico. Sem se importar, outros usuários trazem a ideia de que homens bissexuais usufruem dos 'privilégios' das pessoas heterossexuais quando se relacionam com mulheres; segundo o internauta 17, “se um homem deseja outro homem, mesmo estando com uma mulher, é porque é um gay enrustido”. Essa fala implica na crença de que a identidade bissexual é um subterfúgio mentiroso para negar a homossexualidade.

Figura 4 - O GIF mostra outra personalidade popular na internet no período da discussão, Lolly Vômito, chutando

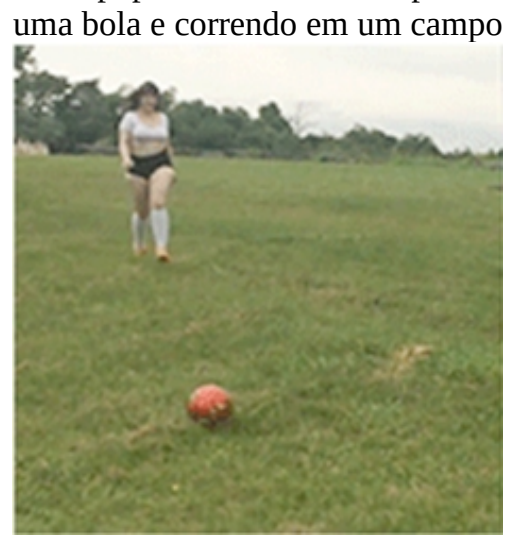

Fonte: https://bityli.com/0uBiF 
A apresentação da bissexualidade como algo perigoso, como foi inicialmente sugerido pelo internauta 14, retorna ao tópico. Quando um usuário pergunta sobre a orientação sexual de alguém que conheceu, outro ‘denuncia’ a bissexualidade como um crime:

Internauta 18: tenho um amigo que namorou 2 anos com uma menina e hj ta namorando um menino

Ele é oq então porra? [Fig. 5]

Internauta 14: [respondendo ao internauta 18] Bissexual e a menina foi uma das vítimas. Agora a vítima é um menino

MEU DEUS MEU DEUS

O certo é evita-los. Os danos são irreversíveis

Internauta 16: Pior que é isso mesmo.

A lista de gente que eu conheço que tiveram algo com bissexuais e saíram decepcionados porque depois de abuso, manipulação e pressão, eles simplesmente destroem a pessoa e depois saem pra namorar com o ado mais aceito pela sociedade. É isso que vai acontecer com esse menino, coitado

O internauta 18 mostra-se confuso sobre a sexualidade de um amigo que namorou com uma moça e depois começou a namorar um rapaz, sem saber se ele seria heterossexual, homossexual ou bissexual. A resposta que ele recebe é um tanto enigmática; o usuário 14 fala em “vítimas” do jovem citado, e acrescenta que pessoas bissexuais devem ser evitadas: “Os danos são irreversíveis”. Mas por que os namorados de uma pessoa bissexual seriam suas 'vítimas'? Quais são os danos que os bissexuais causam àqueles com quem se relacionam? Um novo comentário responde a essa pergunta, aludindo a vários conhecidos que namoraram bissexuais e sofreram abuso, manipulação e pressão: “Eles simplesmente destroem a pessoa e depois saem pra namorar com o lado mais aceito pela sociedade”. As referências a homens bissexuais que trocam homens gays por mulheres, em busca de 'aceitação social', se repetem. Embora recorrentes, essas ideias seguem uma estranha lógica de associar orientação sexual e caráter, definindo os indivíduos bissexuais como, por regra, manipuladores e abusivos em seus relacionamentos.

Figura 5 - Uma jovem toda vestida de rosa posa sorrindo com uma bolsa ao lado de um quadro, também rosa, no qual está escrito "A Luta Continua”

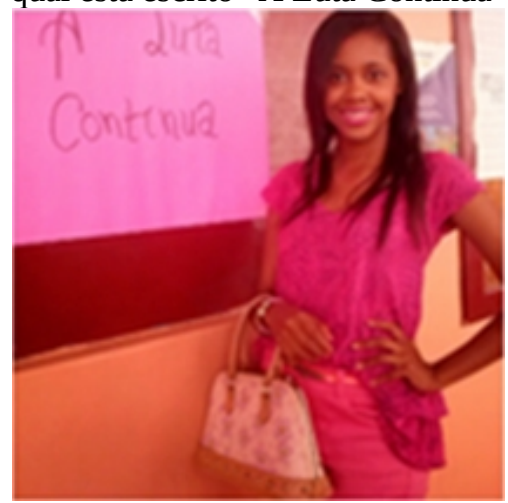

Fonte: https://bityli.com/ME7vQ 
A Figura 5 não se trata de um GIF, mas de uma imagem em outro formato, sem movimento. É difícil dizer se o internauta 18, ao usá-la, quis demonstrar de forma sarcástica que não se importava de verdade com a questão, ou se apenas quis ilustrar o seu comentário sem se preocupar com o sentido dela. Quando outro usuário do fórum atribui conotações ao ato sexual com um homem bissexual, o internauta 14 traz de volta a sua associação da bissexualidade ao perigo, agora esclarecendo que trata da transmissão de doenças:

Internauta 19: Eu mesmo quando comi um bi fiquei com um tesão enorme. Pensar que tô comendo alguém que come mulheres. O cara escolheu dar o cu pra mim, ao invés de ir comer uma mulher, é quase a sensação de comer um hétero. [acrescenta uma imagem que não está mais disponível no fórum]

Internauta 14: [respondendo ao internauta 19] Espero q vc tenha colocado no mínimo 6 camisinhas, uma em cima da outra, no teu pau. Vc tomou um banho de criolina + querosene e tacou fogo np corpo e em seguida pulou na água com sal grosso?

Caso contrário..... é melhor vc procurar um posto de saúde

Se o internauta 19 afirmou sentir tesão, como em um fetiche, de "comer alguém que come mulheres”, aproximando os homens bissexuais dos heterossexuais, a resposta debochada que recebeu retorna ao estigma da bissexualidade como vetor de transmissão da Aids. A forma violenta como estes jovens gays referem-se aos bissexuais e lhe transmitem os estigmas com os quais eles próprios provavelmente já tiveram ou terão que lidar, evidencia a heterogeneidade e os conflitos mascarados pela homogeneização das populações LGBT. Lembrando muito alguns insultos homofóbicos, estes jovens homossexuais cultivam a ideia de que os bissexuais, por si só, têm comportamentos imorais.

Outro usuário do fórum reafirma, em tom irônico, que a bissexualidade é uma mentira:

Internauta 12: onde um homem que da o cu como uma cadelinha consegue chupar uma xana depois por tesao? kkkkkkkkk assumam logo que são gays e ficam com mulheres para agradar a família e a sociedade

Internauta 17: Bissexuais, se existem, estão levando uma vida heterossexual

Se encontram prazer em uma mulher, não existe a menor possibilidade de passar por todos os perrengues que a homossexualidade traz

Os caras que têm uma namorada ou uma esposa e vão procurar um macho na rua, certamente não é bissexual

É um homossexual que tenta disfarçar seu desejo reprimido com uma relação bem vista aos olhos da sociedade

Internauta 16: E quem sofre na mão desses, é sempre o(a) homossexual que tem coragem de se assumir

O internauta 12 ri da possibilidade de um mesmo homem assumir os papéis que supostamente seriam limitados ao heterossexual e ao homossexual. Sua fala e os comentários seguintes reforçam a ideia, já repetitiva, de que o bissexual na verdade é um homossexual que tem medo da homofobia, e até mesmo que 'usa' os homossexuais que se assumem. Como os seus pares, este internauta parece especialmente incomodado com a bissexualidade masculina. 
Mas a discussão assume contornos políticos explícitos quando um usuário afirma que os homens bissexuais não são confiáveis para o movimento LGBT.

\author{
Internauta 20: Ai gente, me desculpa falar \\ mas o homem bissexual no meio lgbtq é o que tem o discurso mais raso \\ vcs já repararam isso? Eles são os mais privilegiados do nosso meio. Pra eles tanto faz \\ estar ao ado das pocs ou lampadando a cara delas \\ quando eu tiver a oportunidade de ir pra esses congressos de DCE LGBTQI+, eu vou \\ levantar esse questionamento e vou pisar muito nesses otários [Figura 6] \\ Internauta 3: [respondendo ao internauta 20] Nada de novo sob o sol. Eles se escoram \\ nessa classe, muitos são gays mesmo.
}

O usuário 20 mostra-se incomodado com a inserção de bissexuais no movimento LGBT, por entender que eles transitam com facilidade entre o lado do agressor (heterossexual) e do agredido (homossexual), preferindo, assim, o lado do agressor. A expressão 'lampadar’ faz referência a um episódio homofóbico ocorrido na cidade de São Paulo em 2010, e que repercutiu em todo o país, no qual três rapazes homossexuais foram atacados por um grupo de jovens heterossexuais enquanto caminhavam em uma calçada. Na ocasião, um dos agressores golpeou uma das vítimas de surpresa com uma lâmpada fluorescente, dando início a um espancamento (GOMES, 2018).

Figura 6 - No reality show A Fazenda, a influenciadora digital Nadja Pessoa ouve incomodada os argumentos de alguém

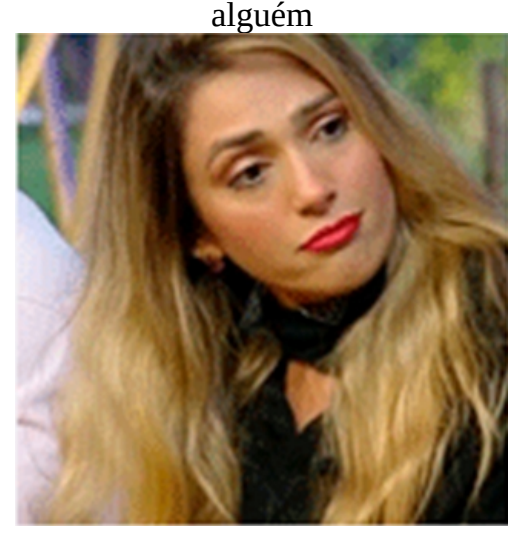

Fonte: https://bityli.com/fFgy0

A resposta positiva do internauta 3 recebe diz que bissexuais se 'escoram' no que ele chama de ‘comunidade’ e afirma que muitos, na verdade, são gays. Embora pareça inclusivo ao usar a sigla LGBTQI+, o internauta 20 se revolta ao perceber em assembleias da comunidade indivíduos que, para ele, estão mais próximos dos privilégios heterossexuais do que todos os demais grupos da sigla, e que expressam um discurso político superficial, dada a sua posição de conforto. Em sua fala, a homofobia parece ser a única forma de discriminação entre grupos definidos por orientação sexual, ignorando todos os comentários preconceituosos presentes no mesmo tópico em que se expressa. Neste momento da discussão, outros usuários discordaram do internauta 20, chamando-lhe de 'doente', ao que ele previsivelmente respondeu com deboche; 
seguiu-se uma troca generalizada de farpas e mesmo de comentários racistas, que não reproduzo aqui por falta de espaço e de foco entre os usuários.

A ideia de que pessoas bissexuais sofrem preconceito, ou, ainda, um preconceito particular, não parece muito popular:

Internauta 15: B é a letra que sofre mais preconceito dentro da cmm, e esse tópico está aí pra provar isso [Figura 4]

Internauta 16: [respondendo ao internauta 15]

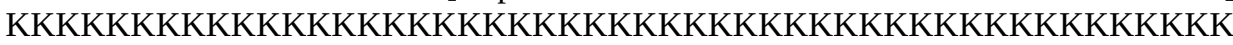
AHAM

SOFRE SIM

Internauta 17: [respondendo ao internauta 15] Tem que sofrer mesmo, porque vocês usam a farsa de gostar de mulher para terem uma aceitação maior dentro da sociedade Faz um experimento com a sua bissexualidade

Saia de mãos dadas com um homem e depois com uma mulher

E depois volte aqui para falar sobre quem sofre mais [Figura 7]

O comentário que aponta a discriminação de bissexuais dentro do meio LGBT, provoca risos forçados. O internauta 17, usando a Figura 7, afirma que homens bissexuais merecem sofrer preconceito, pois podem escolher entre sair na rua com um homem (sendo agredidos) e sair com uma mulher (sendo respeitados). É provável que suas afirmações tenham sido publicadas apenas com o intuito de provocar e debochar da indignação do internauta 15, e que por isso tenha exagerado, como o internauta 16 exagerou ao reproduzir a intensidade de sua suposta risada. Ainda assim, sua retórica não é muito diferente das de outros usuários, que dão a entender que um homem bissexual pode escolher por qual gênero se interessar e se relacionar conforme for conveniente; o internauta 17 compara a experiência homossexual com a heterossexual, indicando a experiência bissexual como uma escolha livre entre as duas.

Figura 7 - Gretchen, de braços cruzados, escuta a fala de alguém, sinalizando desconfiança e desaprovação

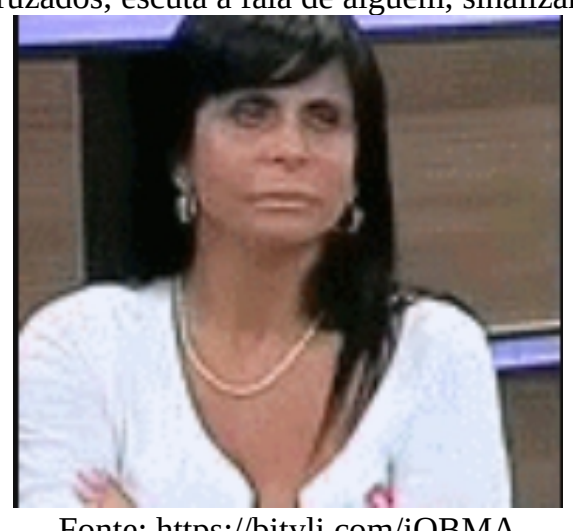

Fonte: https://bityli.com/iQBMA

A dificuldade em acreditar que uma mesma pessoa possa desejar homens e mulheres parece então relacionada à fixidez que o binário homo-hétero encontra na sociedade; seguindo esta lógica, se o desejo bissexual fosse possível, a sociedade não seria dividida da forma que é. 
Os internautas 16 e 17 mostram, ao longo da discussão, que negam a bissexualidade por não verem nada de específico para a população bissexual em termos sociais e políticos.

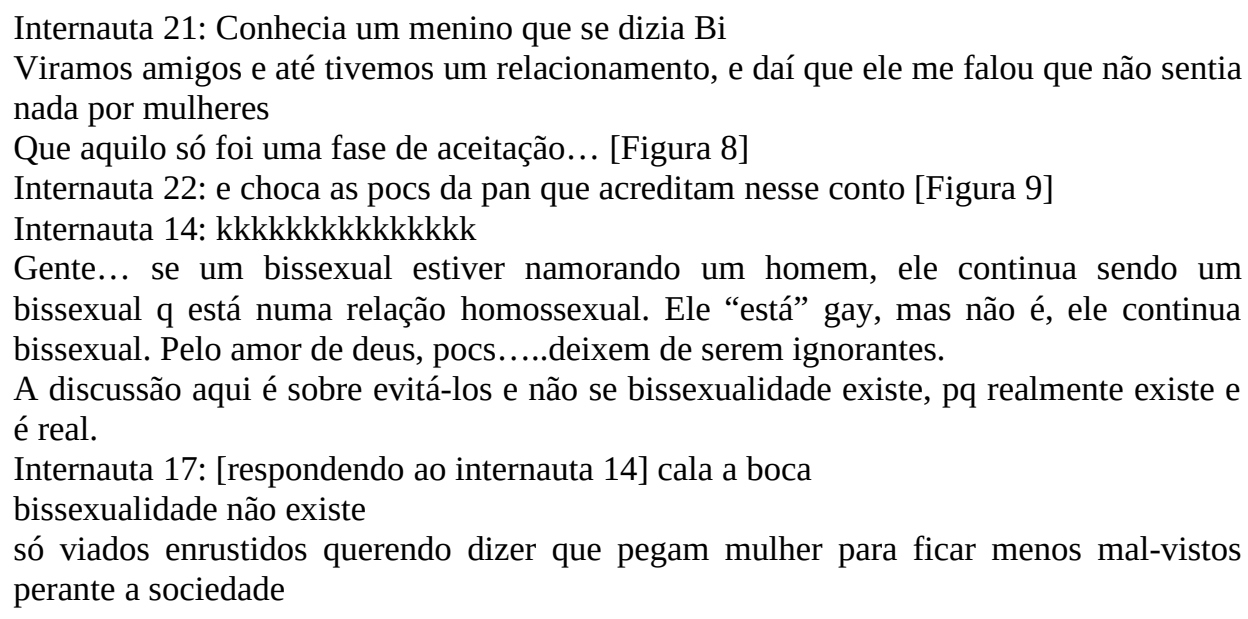

O internauta 14 é o que mais insiste em seu ponto de vista, e a noção de que bissexuais eventualmente estão gays, em sua retórica de pureza e perigo, faz novo eco a incômodos de comunidades políticas de lésbicas (LEÃO, 2018). Mas as diferentes definições de bissexualidade, embora quase todas sejam negativas, entram em conflito. No momento em que um usuário declara que ouviu alguém confessar a falsidade de sua identidade bissexual, outro internauta toma isso como uma evidência de que a bissexualidade, por si só, é falsa.

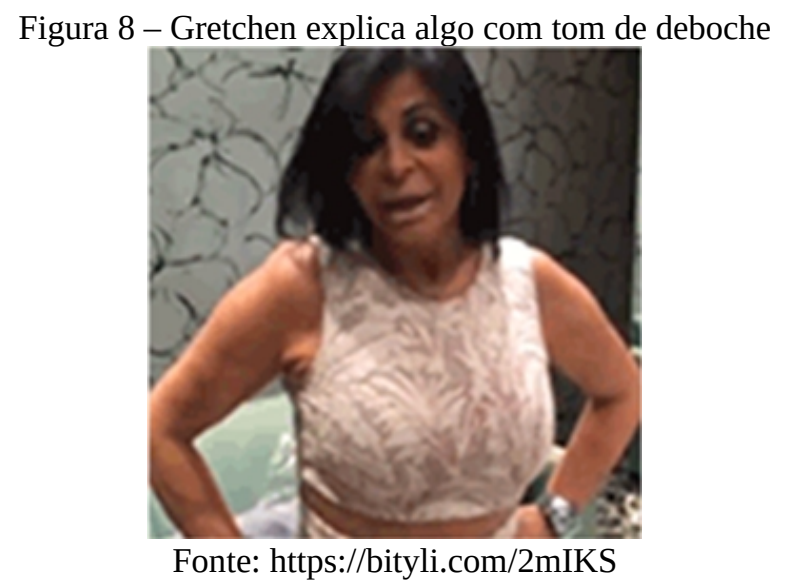

Ainda que não seja tão lógico basear-se em um exemplo para negar a existência de toda uma orientação sexual, o internauta 22 parece convencido de que o indivíduo bissexual é sempre alguém homossexual com dificuldades de lidar com a própria sexualidade. Para ele, a confissão de um falso bissexual seria uma resposta para os usuários do fórum que acreditam no 'conto [de fadas]' da bissexualidade. O GIF de Inês Brasil que o usuário acrescenta a seu comentário não parece se referir ao seu próprio tom, mas sim à falta de inteligência que ele atribui àqueles que acreditam que a existência de pessoas bissexuais é possível, seja os que as defendem ou os que 
as denunciam. Enquanto o internauta 14 reduz a bissexualidade a um comportamento (perigoso), o internauta 17 reage com a agressividade típica dos usuários do fórum para defender que a bissexualidade não existe. Este momento da discussão foi interessante por mostrar as três ‘estratégias’ do apagamento bissexual sugeridas por Kenji Yoshino em conflito: o apagamento de classe (internauta 17), o apagamento individual (internauta 22) e a deslegitimação (internauta 14).

Figura 9 - Outra figura memetizada, Inês Brasil participa de um programa de TV e parece estar confusa com o que o apresentador lhe explica

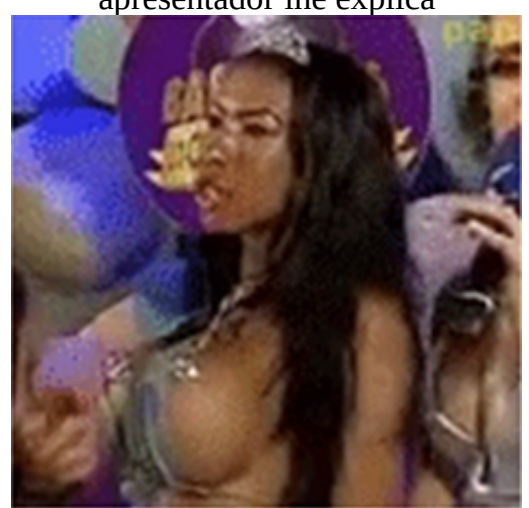

Fonte: https://bityli.com/O4Mze

Enquanto um usuário se revolta contra a discussão, sem especificar qualquer uma das definições dos demais, o internauta 24 fala de sua própria experiência com o desejo bissexual, afirmando que suas preferências se alternam sazonalmente. Mas essas posições são inferiores em número. Um último internauta responde definindo a bissexualidade como indecisão, e acrescenta que ela que lhe dá 'pena':

Internauta 23: Porra respeitem a bissexualidade alheia caralho Internauta 24: Acontece more

Eu sou bi só tive namoradas de um ano pra ca que começou a vontade de transar com homens

Sempre senti atração mas só por homens da tv

Nunca tinha tido atração por homens "reais"

E sempre alterna tem época 1ue eu prefiro mulbee

E outras homens

Internauta 14: [respondendo ao internauta 24] Deve ser triste viver a vida toda nessa indecisão

Ainda bem q nasci gay

$\mathrm{Q}$ vida triste a sua

Sinto pena

De fato, a força com que a oposição homossexual-heterossexual se impõe, negando qualquer possibilidade para além dela, marca a incredulidade, a desconfiança, o desprezo e a revolta que muitos homossexuais têm em relação à bissexualidade. Vários dos comentários aqui falam da localização do sujeito bissexual em relação à homofobia para decidir se a bissexualidade existe ou não. Essa concepção binária da sexualidade humana coloca 
heterossexualidade e homossexualidade em posições totalmente opostas, sendo que, por convenção, o desejo sexual e a atração romântica de todo indivíduo deveriam corresponder a um dos dois polos ou se aproximar mais de um deles. Por esta razão, a leitura binária renega a bissexualidade a um local de ambiguidade, indecisão, falsidade e descontrole, isso quando é reconhecida a sua existência, embora, para Yoshino, todos esses locais são maneiras de negá-la.

Por fim, a argumentação sustentou-se na rigidez dos papéis de gênero. O internauta 12 definiu sua homossexualidade como a atração pelo masculino, sugerindo que a suposta atração por mais de um gênero seria fruto da pressão social, enquanto o binário de gênero seria o fundamento para desejos que ele pareceu considerar naturais:

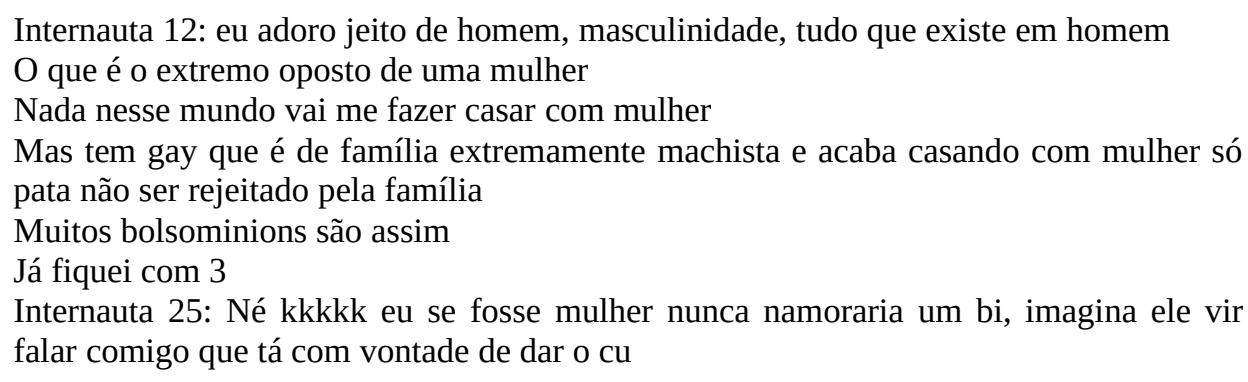

A oposição binária homo-hétero, cuja rigidez originaria a bifobia, está também atrelado ao binário homem-mulher. Para o internauta 12, sua homossexualidade depende da noção de masculinidade (sendo esta oposta à feminilidade), baseando-se no binarismo que, diga-se de passagem, também é usado como razão da própria homofobia (BORRILLO, 2010). O internauta 25 sugere que o mesmo valeria para as pessoas heterossexuais. Tudo isso para negar a possibilidade de que a bissexualidade existe.

Se a bifobia se fundamenta nos binários de gênero e sexualidade, porém, não quer dizer que as pessoas bissexuais irão se opor automaticamente a esses binários. Ismar Inácio dos Santos Filho (2012), em sua própria netnografia, notou que alguns homens bissexuais assumiam exclusivamente o papel 'ativo' (havia também os que sempre eram 'passivos') nas relações sexuais. Eles afirmavam que o homem bissexual não poderia ser jamais passivo, algo incompatível com a masculinidade; reproduziam assim a lógica heteronormativa que encerra a vida sexual nos papéis de macho e de fêmea. Mesmo sendo eles próprios bissexuais, pensavam e viviam a sexualidade segundo os princípios que os jovens homossexuais, que lemos aqui, usam para negar a existência da bissexualidade. Por outro lado, alguns homens bissexuais na pesquisa de Santos Filho não se limitavam a padrões binários ou normativos, tornando a relação entre a identidade bissexual e os padrões de gênero uma grande variável. 


\title{
5. A 'lamúria’ da bifobia
}

Na sessão de comentários da página Resistência Gay, não vemos GIFs. A página está hospedada no site Facebook, rede social que permite o compartilhamento de conteúdo multimídia de pessoas e grupos com os demais usuários. Uma vez que o Facebook permite a reprodução de GIFs animados em publicações e comentários, a ausência deles aqui sugere o tom mais sério das discussões desta página específica. Com uma proposta bem diferente dos tópicos de discussão do fórum, que às vezes beiram o cinismo, uma publicação específica da página pode nos ajudar a separar o que é preconceito do que é provocação e escárnio. Seu perfil de público é essencialmente de homens gays, como no fórum Pan, mas seu tom se afasta do deboche e se aproxima da indignação. Apesar do conteúdo mais sério, isso não quer dizer que a ironia desapareça por completo neste outro espaço. Publicada em agosto de 2017, a publicação consiste em um texto com algumas informações enumeradas; ela começa da seguinte maneira:

\begin{abstract}
Um homem bissexual escreveu um texto classificando esta página como 'podre', condenando-a por postar notícia sobre um bissexual que matou um gay. Ele acusa a página de propagar ódio contra bissexuais por ressaltarmos a orientação sexual do criminoso. E diz que os comentários na página provam a existência de 'Bifobia'. Ele ainda afirma que homens gays também produzem relacionamentos tóxicos e abusivos e que ele próprio já foi vítima de vários gays. Vamos por partes, como diria o esquartejador. (RESISTÊNCIA GAY, 2017)
\end{abstract}

A página, então, lista cinco argumentos contra-atacando a acusação sofrida, todos acompanhados de links para demonstrar fundamentação. O primeiro diz que a baixa popularidade dos bissexuais não seria gratuita, pois eles não estão interessados em se aproximar dos gays ou de sua militância; o link complementar é de uma matéria sobre homens bissexuais que se relacionam com mulheres e escondem sua orientação sexual delas. O segundo faz menção a uma pesquisa realizada pelo blog SouBi (2016), segundo a qual 55\% dos bissexuais já falaram mal de gays e mesmo de bissexuais apenas para agradar pessoas heterossexuais, fingindo concordar com discursos de ódio em seus ambientes de convívio. O blog responsável pela pesquisa também apresenta uma porcentagem próxima (48\%) do medo da reprovação sentido por pessoas bissexuais, o que sugere que esse comportamento pode ser um esforço por segurança; isso é ignorado pelos autores do texto da página no Facebook, que usam a pesquisa como evidência de que bissexuais estão em uma posição confortável, pois não precisam fingir que têm atração pelo gênero dado como 'oposto’.

O terceiro argumento seria o conforto do modo de vida heterossexual, que seria preferido por bissexuais; é apresentada como fonte uma pesquisa do Pew Research Center (PARKER, 2015) que indicou a baixa importância conferida por bissexuais estadunidenses à sua própria 
orientação sexual (indício de sua segurança) e uma tendência gritante (84\%) a se relacionar com pessoas do sexo oposto. Neste momento, a página já parece menos se defender e mais advogar pela marginalização dos bissexuais no meio LGBT. O quarto argumento, portanto, seria mais direto: “Qual a contribuição da comunidade bissexual para a causa da libertação gay?”; a alusão agora é a figura histórica do militante alemão Adolf Brand, do começo do século XX. Segundo o texto da página, Brand foi importante por criar a primeira revista homossexual da história (chamada Der Eigene) e participar do Comitê Científico Humanitário (“o primeiro grupo gay do mundo”) ao lado de Magnus Hirschfeld. A publicação sugere que Brand foi bissexual por ter se casado com uma mulher e defender o retorno ao modelo erótico grego, em que homens se relacionavam com rapazes e mulheres:

Sintomaticamente Brand logo retirou-se do Comitê Científico para fundar seu próprio grupo; no processo ele difamava e ridicularizava os ativistas do Comitê, além de ter procurado apoio dos nazistas. Quando o nazismo tomou o poder na Alemanha, enviou o presidente do Comitê Científico Kurt Hiller para um campo de concentração, mas ninguém no regime tocou um único fio de cabelo de Brand, que continuou a viver com sua esposa até 1945 quando uma bomba dos aliados destruiu sua casa, matando ele e a mulher. (RESISTÊNCIA GAY, 2017, grifo meu)

A argumentação aproxima Adolf Brand (exemplo eleito para representar o papel dos bissexuais junto à militância gay) dos nazistas, que perseguiram homossexuais e enviaram milhares para prisões e campos de concentração; a página salienta que a morte de Brand foi causada por um ataque dos aliados na Segunda Guerra Mundial. Harry Oosterhuis (1991), estudioso do movimento homossexual da Alemanha pré-nazista, afirma ter encontrado uma evidência de uma conexão de Brand com um membro do partido de Hitler, mas conta que a casa do militante ainda assim foi invadida pelos nazistas diversas vezes. Segundo Oosterhuis, a relação de Brand e o Comitê foi marcada por sucessivos conflitos e reconciliações, tendo Brand comemorado o seu aniversário de cinquenta anos no Instituto de Ciências Sexuais fundado por Magnus Hirschfeld, com direito a um discurso deste. Sobre a diferença do tratamento que Brand recebeu em relação aos demais, o pesquisador não é tão categórico ao ver o casamento (ou a bissexualidade) como sua salvaguarda, e lembra que ele não era judeu, diferente de Hirschfeld e Hiller, militantes homossexuais que foram sumariamente perseguidos pelo governo nazista.

O ‘argumento’ final da página é ainda menos sutil: “É muita desonestidade desse bissexual vir reclamar de 'demonização' e ativismo de ódio. Essa pessoa é notoriamente gayfóbica, e constantemente vive cuspindo generalizações odiosas sobre os gays”. E, comparando o indivíduo a uma outra pessoa, uma certa ativista transexual, completa: "quando alguém da sua classe faz algo errado socialmente, trata-se de um problema daquele indivíduo 
específico. Quando um gay faz a mesma coisa, [vocês falam que] é um problema do grupo, da comunidade gay".

O desenvolvimento argumentativo do texto baseou-se na tendência histórica de situar o bissexual na dicotomia hétero-homo. Para algumas pessoas homossexuais (não é possível aqui precisar quantas, em quais contextos ou qual o nível de difusão dessas ideias), como aparece nesta publicação e nas discussões do fórum Pan, bissexuais estão em uma posição confortável frente a violências sofridas por elas e até se aproveitam disso, aproximando-se de homossexuais apenas quando é conveniente. E, a despeito da surpreendente associação sugerida entre militantes bissexuais (em Adolf Brand) e regimes homofóbicos (no nazismo), o texto recebe muitos comentários positivos. Atualmente, o Facebook oferece seis opções para os usuários reagirem às postagens e aos comentários: “Curti”, “Amei”, “Haha”, “Uau”, “Triste”, “Grr”; nos comentários reproduzidos a seguir, indico como outros usuários reagiram a eles:

Internauta 26: Pior que sou bi e conheci mais bi q trauam por mulher por homem, e não se assumem, eles msm causa essa ma impreça e onde meio q todos saem como ruins : (:) inclusive eu. [o comentário provocou duas reações “Curti”]

Internauta 27: Olha eu me relacionei com bissexuais e aprendi que eles querem sós exo e nada mais [dez reações: "Curti” e "Triste"]

Internauta 28: bifobia é uma realidade entre mulheres, já entre homossexuais masculinos é tipo misandria, heterofobia, racismo reverso: vitimismo do opressor [quatro reações: "Curti” e “Amei”]

Internauta 29: Bissexuais estão hierarquicamente acima de gays na hierarquia das sexualidades

Na puberdade por exemplo, o bissexual não sofre a solidão afetiva que o menino gay sofre porque para o menino bi tá super confortável pegar as meninas. [uma reação "Amei”]

Internauta 30: Semi-hétero nem é gente. [uma reação “Curti”]

Os internautas 26-30 retornam às ideias de que bissexuais são promíscuos ou que estão em uma posição confortável, não estando sujeitos a exclusão. Nenhuma novidade até aqui. Mas o primeiro comentário destacado, embora quase ilegível, é de um homem bissexual e dá a entender que pessoas bissexuais têm comportamentos reprováveis, mas que não deveriam ser culpabilizadas por isso. Este estranho raciocínio, no contexto em que foi apresentado, parece uma resposta a alguns comentários de homens gays afirmando que não se relacionam com bissexuais, e que não estão sendo 'bifóbicos’ ao ter tal comportamento.

Para além destes internautas, dezenas de outros comentários da publicação corroboram as mesmas ideias enumeradas na lista dos ativistas bissexuais apresentada por Camila Dias Cavalcanti (2007) e observadas nas discussões do fórum Pan. Afirmações, por exemplo, de que “ninguém é xingado de bissexual no ônibus” e que, portanto, a bifobia seria uma 'lamúria'. A narrativa da bifobia, como se vê é fonte de muita disputa no movimento LGBT (LEÃO, 2018). Ativistas e pesquisadores preocupados com a posição social da bissexualidade têm feito menção 
a estatísticas disponíveis na atualidade que apontam como as pressões sofridas têm tido efeitos na vida de pessoas bissexuais em termos de população. Quando comparadas às populações hétero e homo, as pessoas bissexuais seriam mais recorrentemente vítimas de violências sexuais nos Estados Unidos (NATIONAL INTIMATE PATNER AND SEXUAL VIOLENCE SURVEY, 2010), e a de maior tendência ao isolamento, desenvolvimento de vícios, pensamentos suicidas, transtornos mentais (depressão, ansiedade, síndrome do pânico) e mesmo à pobreza em diversos países (PARSHALL, 2017; ROSS, 2018; SAN FRANCISCO HUMAN RIGHTS COMISSION, 2011). A experiência dos indivíduos bissexuais, ao contrário do que supõem os responsáveis pela publicação e seus seguidores, afinal, estaria além da sua posição em relação à homofobia. Ou melhor, existiria uma experiência bissexual.

É claro, para compreender as atitudes preconceituosas como um processo social amplo, seria necessário olhar para os sentidos de negação da bissexualidade nas diferentes instituições e formas de pensamento da sociedade, o que passou a ser chamado mais precisamente de apagamento bissexual (ANGELIDES, 2006; YOSHINO, 2000). Aqui, nos comentários de quase trinta jovens gays, as afirmações de que bissexuais não sofrem preconceito partem do pressuposto de que eles não sofrem homofobia da mesma forma que os homossexuais, o que é evidente, mas seus acusadores apressam-se em negar qualquer processo que possa existir para além da lógica que vivenciam. O internauta 30, que comenta com um tom jocoso que "semihétero nem é gente”, resume essa lógica.

\section{6. [Tópico OFF]: Conclusões}

Este estudo não oferece meios para pensar a bifobia como um processo de 'opressão' (muito menos estrutural), como querem autores como Miguel Obradors-Campos e Shiri Eisner, pois concentrou-se em espaços bem específicos de um grupo marginalizado que tem acesso limitado ao poder. No entanto, as falas com relação à bissexualidade em ambos os espaços observados refletem uma preocupação política destes internautas específicos com a sua própria condição social enquanto homossexuais, e não é por acaso que eles preferem se referir aos homens bissexuais ao expressar seus incômodos. Ainda assim, a sua ojeriza à bissexualidade e às pessoas bissexuais (particularmente na suposta ameaça representada pela bissexualidade e por seus atributos negativos) mostrou-se quase sempre relacionada à delimitação estrita entre a homossexualidade e a heterossexualidade, que a bissexualidade desafiaria.

O que Yoshino chamou de 'investimento da deslegitimação’ apareceu nos comentários negativos apresentados aqui sobre as pessoas bissexuais que aludiram à 1. promiscuidade 
atribuída, além de acusações de infidelidade, desvio de caráter e mesmo da transmissão do HIV; e 2. à concepção de que bissexuais (principalmente os homens) usufruem dos mesmos 'privilégios' que os heterossexuais. Sobre a bissexualidade como uma condição de privilégio, os internautas partiam da classificação binária e dicotômica que se fecha em homossexualidade e heterossexualidade, e que deixa para a bissexualidade um suposto poder de escolher qual posição assumir na sociedade, pois não teria um lugar para si. Segundo os seus comentários, a aceitação de instituições como a família e a segurança contra os ataques homofóbicos levariam as pessoas bissexuais a preferir viver como heterossexuais, envolvendo-se com homossexuais apenas sexualmente e mesmo assumindo o papel de seus algozes.

A divisão tão acirrada entre os papéis socialmente atribuídos ao sujeito heterossexual e ao homossexual confunde alguns dos internautas: como poderia um homem desejar outro homem e também uma mulher? Diversos dos comentários lidos acima questionaram como pode existir ou ser lógica a atração por mais de um gênero, partindo do princípio de que os gêneros, os sexos e suas expressões são rigidamente delimitados. Seguindo a teoria de Kenji Yoshino, segundo a qual o apagamento bissexual é uma forma de fundamentar o binário homo-hétero e a divisão entre os gêneros, os comentários bifóbicos apresentados neste artigo manifestam (além da própria ideia binária da sexualidade) uma visão normativa do gênero. Uma importante diferença da análise empreendida aqui é que as representações e definições negativas da bissexualidade, tão esquematizadas por outros autores, não são um conjunto de discursos consonantes, mas uma variedade de entendimentos que, apesar de um princípio lógico mais ou menos estável, entram em conflito e até mesmo se contradizem.

\section{Referências}

ANGELIDES, S. Historicizing (bi)sexuality. Journal of Homosexuality, New York, v. 52, n. 1-2, p. 125-158, 2006.

AZEVEDO, Á. S. R. Jornalismo e diversidade sexual: construções discursivas sobre a bissexualidade no portal G1. 2016. Monografia (Bacharelado em Comunicação Social - Jornalismo) - Universidade Federal do Pará, Belém, 2016.

BORRILLO, D. Homofobia: história e crítica de um preconceito. Belo Horizonte: Autêntica, 2010.

CALLIS, A. S. The black sheep of the pink flock: labels, stigma, and bisexual identity. Journal of Bisexuality, New York, v. 13, n. 1, p. 82105, 2013.

CASTELLS, M. A sociedade em rede: 1. São Paulo: Paz e Terra, 2002. 
CAVALCANTI, C. D. Visíveis e invisíveis: práticas e identidade bissexual. 2007. Dissertação (Mestrado em Sociologia) - Universidade Federal de Pernambuco, Recife, 2007.

DYAR, C.; FEINSTEIN, B. A. Binegativity: attitudes toward and stereotypes about bisexual individuals. In: SWAN, D. J.; HABIBI, S. (org.). Bisexuality: theories, research, and recommendations for the invisible sexuality. New York: Springer, 2018.

EISNER, S. Bi: notes for a bisexual revolution. Berkeley: Seal Press, 2013.

FACCHINI, R. Sopa de letrinhas?: movimento homossexual e produção de identidades coletivas nos anos 1990. Rio de Janeiro: Garamond, 2005.

GOMES, P. Acusados de ataque com lâmpada na Paulista são multados em R\$ 129 mil. Folha de S.Paulo, São Paulo, 2018. Disponível em: https://bityli.com/JKzMO. Acesso em: 8 jan. 2020.

HARRISON, M. 8 times Lady Gaga earned her 'Gay Icon' title. Billboard, New York, 2017. Disponível em: https://bityli.com/b55D7. Acesso em: 2 jan. 2019.

HINE, Christine. Etnografia virtual. Barcelona: Editorial UOC, 2000.

JAEGER, M. B. Experiências de minas bissexuais: políticas identitárias e processos de marginalização. 2018. Dissertação (Mestrado em Psicologia) - Universidade Federal de Santa Catarina, Florianópolis, 2018.

LEÃO, M. Os unicórnios no fim do arco-íris: bissexualidade feminina, identidades e política no Seminário Nacional de Lésbicas e Mulheres Bissexuais. 2018. Dissertação (Mestrado em Medicina Social) Universidade do Estado do Rio de Janeiro, Rio de Janeiro, 2018.

LEWIS, E. S. “Não é uma fase”: construções identitárias em narrativas de ativistas LGBT que se identificam como bissexuais. 2012. Dissertação (Mestrado em Estudos da Linguagem) - Pontifícia Universidade Católica do Rio de Janeiro, Rio de Janeiro, 2012.

MACRAE, E. A construção da igualdade: política e identidade homossexual no Brasil da “abertura”. Salvador: EDUFBA, 2018.

MULICK, P. S; WRIGHT JR, L. W. Examining the existence of biphobia in the heterosexual and homosexual populations. Journal of Bisexuality, New York, v. 2, n. 2, p. 47-64, 2002.

NATIONAL INTIMATE PARTNER AND SEXUAL VIOLENCE SURVEY. 2010 findings on victimization by sexual orientation. Atlanta: National Center for Injury Prevention and Control Centers for Disease Control and Prevention, 2013.

OBRADORS-CAMPOS, M. Deconstructing biphobia. Journal of Bisexuality, New York, v. 11, n. 2-3, p. 207-226, 2011. 
OOSTERHUIS, H. Homosexuality and male bonding in pre-nazi Germany: the youth movement, the gay movement, and male bonding before Hitler’s rise. New York: Harrington Park Press, 1991.

PARSHALL, H. Bisexual health awareness month: mental health in the bisexual community. Human Rights Campaign, 2017. Disponível em: https://bityli.com/Y7F1L. Acesso em: 2 mar. 2020.

PARKER, K. Among LGBT americans, bisexuals stand out when it comes to identity, acceptance. Pew Research Center, Washington, D.C, 2015. Disponível em: https://bityli.com/jut3w. Acesso em: 1 ago. 2019.

REYNOLDS, D. Is Lady Gaga LGBT or an ally?. Advocate, Los Angeles, 2017. Disponível em: https://bityli.com/hgCZM. Acesso em: 23 fev. 2020.

ROSS, L. E. et al. Prevalence of depression and anxiety among bisexual people compared to gay, lesbian, and heterosexual individuals: a systematic review and meta-analysis. The Journal of Sex Research, Abingdon, v. 55, n. 4-5, p. 435-456, 2018.

SAN FRANCISCO HUMAN RIGHTS COMISSION. Bisexual invisibility: impacts and recommendations. San Francisco: LGBT Advisory Committee, 2011.

SOUBI. 55\% dos bissexuais já falaram mal dos LGBTs apenas para agradar. SouBi, 2016. Disponível em: https://bityli.com/BSuwX. Acesso em: 1 ago. 2018.

TENBARGE, K. Lady Gaga's Stonewall speech touched on bisexual exclusion. Insider, New York, 2019. Disponível em: https://bityli.com/NcdAm. Acesso em: 23 fev. 2020.

VÍRGULA. Frank Ocean fala em entrevista sobre experiência de se assumir publicamente homossexual. Vírgula, Brasil, 2012. Disponível em: https://bityli.com/D50oJ. Acesso em: 2 jan. 2019.

YOSHINO, K. The epistemic contract of bisexual erasure. Stanford Law Review, Stanford, v. 52, n. 2, p. 353-478, 2000. 